\title{
Carbapenem antibiotic production in Erwinia carotovora is regulated by CarR, a homologue of the LuxR transcriptional activator
}

\author{
S. McGowan, ${ }^{1}$ M. Sebaihia, ${ }^{1}$ S. Jones, ${ }^{1}$ B. $\mathrm{Yu}_{1}{ }^{2}$ N. Bainton, ${ }^{2}$ P. F. Chan, ${ }^{2}$ \\ B. Bycroft, ${ }^{2}$ G. S. A. B. Stewart, ${ }^{3}$ P. Williams ${ }^{2}$ and G. P. C. Salmond ${ }^{1}$
}

Author for correspondence: G. Salmond. Tel: +44 1203 523534. Fax: +44 1203523701.
e-mail: GP@dna.bio.warwick.ac.uk

1 Department of Biological Sciences, University of Warwick, Coventry CV4 7AL, UK

2,3 Department of Pharmaceutical Sciences ${ }^{2}$ and Department of Applied Biochemistry and Food Science ${ }^{3}$, University of Nottingham, Nottingham, UK

\begin{abstract}
Strain GS101 of Erwinia carotovora makes the carbapenem antibiotic, 1carbapen-2-em-3-carboxylic acid. Mutants defective in antibiotic production can be assigned to two groups, group 1 and group 2 . Group 2 mutants are defective in the carl gene encoding a protein responsible for synthesis of the Lux autoinducer $\mathbf{N}$-(3-oxohexanoyl)-L-homoserine lactone (OHHL), which is required to induce carbapenem synthesis in strain GS101. In this paper we describe the molecular genetic analysis of the group 1 mutants which we presumed were defective in the carbapenem biosynthesis (car) genes. We isolated a cosmid (cWU142) that complemented the group 1 mutants of strain GS101. A small (1.03 kb) subclone of cWU142 complemented most of the group 1 mutants, and the sequence revealed that the relevant gene (carR) encodes a homologue of the Vibrio fischeri LuxR protein. A disproportionately high frequency of carR mutants arose in strain GS101 and this was due to carR acting as a 'hot spot' target for secondary transposition of a Tn5 element in this strain. The CarR protein joins a rapidly growing list of homologues, found in taxonomically unrelated bacteria, which act as positive transcriptional activators of genes encoding diverse metabolic functions, including bioluminescence, exoenzyme virulence factor synthesis, cell division, plasmid conjugation, rhizosphere-specific gene induction, surfactant synthesis and antibiotic production. Most of these LuxR-type regulators have been shown to depend, for their function, on $\mathbf{N}$-acyl homoserine lactones, which act as chemical signals enabling co-ordination of gene expression with cell density.
\end{abstract}

Keywords: Erwinia carotovora, carbapenem, $\beta$-lactam antibiotic, $N$-acyl homoserine lactone, LuxR homologue

\section{INTRODUCTION}

Carbapenem antibiotics are broad-spectrum $\beta$-lactams which tend to be resistant to the clinically encountered $\beta$ lactamases and are effective against both aerobes and anaerobes, including nosocomial pathogens (Bycroft, 1988). Because of this current, and potential, clinical utility of carbapenems, and despite the very recent emergence of carbapenemase-producing clinical isolates

Abbreviations: Car, 1-carbapen-2-em-3-carboxylic acid; OHHL, $\mathrm{N}$-(3oxohexanoyl)-L-homoserine lactone.

The GenBank accession number for the DNA sequence data reported in this paper is U17224.
(Livermore, 1993; Naas \& Nordmann, 1994), there has been a growing interest in the mechanisms of biosynthesis and regulation of such extended-spectrum $\beta$-lactams in the producer organisms. Some Gram-positive bacteria, such as Streptomyces cattleya and Streptomyces penemifaciens, make structurally complex carbapenems, like thienamycin, by a biosynthetic route which is thought to be distinct from that used for the penicillins and cephalosporins (Williamson et al., 1985). However, although there has been some progress in the analysis of synthesis and regulation of thienamycin and some other carbapenems (e.g. Kitano et al., 1985; Williamson et al., 1985; Chen et al., 1993) molecular genetic studies of carbapenem production have been slow because of the relatively poor genetic tractability and slow growth of the producer organisms. 
Some strains of the Gram-negative bacteria Erwinia and Serratia make the simple carbapenem antibiotic 1-carbapen-2-em-3-carboxylic acid (Car; Parker et al., 1982; Bycroft et al., 1987, 1988) and we have initiated a molecular genetic study of carbapenem production in these genetically amenable, fast-growing strains. Previously we isolated carbapenem non-producing mutants $\left(\mathrm{Car}^{-}\right)$of Erwinia carotovora strain GS101 after chemical and transposon mutagenesis (Bainton et al., 1992). These mutants defined two groups on the basis of 'crossfeeding' results in co-cultivation tests. Group 1 mutants were able to crossfeed group 2 mutants and restore Car production in the latter. This crossfeeding was not due to an intermediate in the carbapenem biosynthetic pathway but to a small, freely diffusible signalling molecule, $N$-(3oxohexanoyl)-L-homoserine lactone (OHHL), which is synthesized in a growth-phase-dependent/cell-densitydependent mode (Bainton et al., 1992; Williams et al., 1992; Swift et al., 1994). OHHL is also the Lux autoinducer of Vibrio fischeri and controls cell-densitydependent bioluminescence in that marine bacterium (e.g. see Meighen, 1991).

Recently it has been demonstrated that production of OHHL and structurally related $\mathrm{N}$-acyl homoserine lactones is widespread in bacteria (Bainton et al., 1992; Williams et al., 1992). These discoveries suggested that $N$ acyl homoserine lactones might act to regulate diverse cell-density-dependent physiological processes in different bacteria and recent results are consistent with this hypothesis. $N$-Acyl homoserine lactones regulate bioluminescence ( $V$. fischeri and Vibrio barveyi), carbapenem synthesis (E. carotovora), elastase production (Pseudomonas aeruginosa), Ti plasmid conjugal transfer (Agrobacterium) and exoenzyme virulence factor synthesis ( $E$. carotovora) (Eberhard et al., 1981; Cao \& Meighen, 1989; Bainton et al., 1992; Passador et al., 1993; Zhang et al., 1993; Piper et al., 1993; Jones et al., 1993; Pirhonen et al., 1993). For all of these bacterial hosts, except $V$. harveyi, production of the $N$-acyl homoserine lactone is mediated by a homologue of the $V$. fischeri LuxI protein (e.g. see Fuqua et al., 1994; Swift et al., 1994). In the carbapenem-producing $E$. carotovora strain GS101, the LuxI homologue is Carl (Swift et al., 1993).

In carI mutants (group 2) of strain GS101, carbapenem is not produced, but, in contrast to group 1 mutants, these mutants also show co-ordinate (global) defects in the production of multiple exoenzyme (pectinases, cellulase and proteases) virulence factors (the $\mathrm{Rex}^{-}$phenotype; Regulation of exoenzymes; Jones et al., 1993). Exogenous addition of OHHL simultaneously restores synthesis of the antibiotic $\left(\mathrm{Car}^{+}\right)$and the exoenzymes $\left(\mathrm{Rex}^{+}\right)$in the group 2 mutants confirming that OHHL acts as the global regulatory molecule for multiple, and physiologically diverse, phenotypes in this strain (Jones et al., 1993).

In strain SCRI193 of E. carotovora (which does not make an antibiotic) global regulatory $\mathrm{Rex}^{-}$mutants were also isolated. Some of these are phenotypically similar to the group 2 mutants of strain GS101 in that OHHL restored exoenzyme synthesis in them (Jones et al., 1993).
When we originally investigated $\mathrm{Car}^{-}$mutants of strain GS101 we presumed that the group 1 mutants (Car $^{-}$ $\mathrm{Rex}^{+}$) would be defective in the biosynthetic genes for antibiotic production. However, in this report we describe the molecular analysis of group $1 \mathrm{Car}^{-}$mutants and show that most of these mutants are, in fact, defective in a gene ( $a r R$ ) that encodes a homologue of the $V$. fischeri LuxR protein, a positive transcriptional activator protein.

\section{METHODS}

Bacterial strains and media. Strains used in this study were: Escherichia coli DH1 (Hanahan, 1983); E. coli ESS (a $\beta$-lactam supersensitive indicator strain provided by Beecham Pharmaceuticals); Erwinia carotovora subsp. carotovora strains SCRI193 (Hinton \& Salmond, 1987) and GS101, a restrictionless and modificationless Tn 5 insertion mutant derived from ATCC39048 (Bainton et al., 1992). Isolation of EMS-induced pleiotropic exoenzyme deficient ( $\operatorname{Rex}^{-}$) mutants of SCRI193 (R JP116 and R JP223) has been described before (Jones et al., 1993). The isolation of chemical and transposon-induced $\mathrm{Car}^{-}$mutants of GS101 (Table 1) has been described previously (Bainton et al., 1992). Erwinia and E. coli strains were routinely grown at $30^{\circ} \mathrm{C}$ and $37^{\circ} \mathrm{C}$, respectively, in LB (Miller, 1972). For some exoenzyme assays, cultures of Erwinia were sometimes grown in media supplemented with OHHL (final concentration $1 \mu \mathrm{g}$ $\mathrm{ml}^{-1}$ ).

Isolation of a group 1 cosmid by direct, $\lambda$-mediated cosmid complementation. Chromosomal DNA of the wild-type strain GS101 was prepared and partially digested with SauIIIA, size fractionated, then ligated with BamHI-digested cosmid (pSF6; Selvaraj et al., 1984) DNA. The ligation mixture was packaged into coliphage $\lambda$ heads in vitro using the 'Giga pack gold II' kit (Stratagene). The packaged $\lambda$ cosmid library was used to infect mutant PNP14 carrying the LamB plasmid pTroy9 (see Ellard $e t$ al., 1989) and cosmid-containing transductants were selected on $\mathrm{LB}$ agar plates containing spectinomycin at $50 \mu \mathrm{g} \mathrm{ml} \mathrm{m}^{-1}$. The transductants were screened for restoration of carbapenem production using the halo bioassay test with E. coli ESS as described by Bainton et al. (1992). The complementing cosmid (cWU142) from one such $\mathrm{Car}^{+}$transductant was isolated and used to transform E. coli $\mathrm{DH} 1$ by electroporation. A high titre $\lambda$ cI857 lysate was raised on the transformant, by the method of White et al. (1983), to efficiently package cWU142 and generate a high frequency transducing lysate for this cosmid. That lysate was used to transduce various LamB-containing $\mathrm{Car}^{-}$mutants of E. carotovora with $\mathrm{cWU142}$, using spectinomycin resistance $\left(\mathrm{Sp}^{r}\right)$ as the selectable marker. The general aspects of this LamBbased strategy are described elsewhere (Mulholland \& Salmond, 1995).

Subcloning and sequence analysis. Cosmid cWU142 was digested with EcoRI and released multiple fragments which were cloned back into pSF6 digested with the same enzyme. The resulting subclones were used to transform various Car mutants of GS101, selecting for spectinomycin resistance. One plasmid generated by this shotgun method ( $\mathrm{pWU14203 \text {) }}$ complemented most group 1 mutants. The insert from this subclone was sequenced using the dideoxynucleotide chaintermination procedure (Sanger et al., 1977) and a 'Sequenase kit' (USB). DNA was prepared for sequencing by sonication and ligation of the resulting fragments into M13mp18. Sequence analysis of the car $\mathrm{R}$ region of $\mathrm{Car}^{-}$mutant strains was done by cycle sequencing of PCR-amplified chromosomal DNA. PCR amplification by Taq DNA polymerase (Promega) was carried 
out using synthetic oligonucleotides complementary to sequences $5^{\prime}$ and $3^{\prime}$ of the carR gene, SMCAR1 (5'-GGAATTCGGTATTATGGTTTGG-3') and SMCAR2 (5'-CGTTTGAATTCGTCACATATC- $3^{\prime}$ ), or using one of these in combination with an oligonucleotide complementary to Tn5, TN5PR2 (5'GGGAATTCGGAAGTCAGATCCTGG-3'). Amplification conditions were: $92^{\circ} \mathrm{C}$ for $6 \mathrm{~min} ; 40^{\circ} \mathrm{C}, 2 \mathrm{~min} ; 72^{\circ} \mathrm{C}, 2 \mathrm{~min}$; followed by 25 cycles of $92^{\circ} \mathrm{C}, 1 \mathrm{~min} ; 40^{\circ} \mathrm{C}, 2 \mathrm{~min} ; 72^{\circ} \mathrm{C}$, $2 \mathrm{~min}$. The amplified DNA was prepared for cycle sequencing using a 'Geneclean kit' (Stratech). Cycle sequencing was done using a ' $\Delta$-Taq cycle sequencing kit' (USB) and one of the above oligonucleotides. Analysis of the carR region of mutant PNP21 by this method enabled us to add a further $39 \mathrm{bp}$ of DNA sequence data to the data already generated from pWU14203. Further subcloning of pWU14203 was done based on the sequence information gathered. A $1.03 \mathrm{~kb} S s p \mathrm{I}$ fragment from pWU14203 was cloned in pDAH330 (a chloramphenicol resistant derivative of pIC19R; D. Hodgson, personal communication) digested with EcoRV, to yield plasmid pSMG4. The latter was used to transform $\mathrm{Car}^{-}$strains before screening for complementation.

Gene product identification. A $1.03 \mathrm{~kb} S_{s p \mathrm{I}}$ fragment from pWU14203 was cloned in both orientations into pT7-5 (Tabor \& Richardson, 1985) digested with EcoRV. The resulting plasmids (pSMG5 and pSMG8) were used to express the carR gene by the methods described by Tabor \& Richardson (1985). Protein products were separated by SDS-PAGE and visualized after autoradiography.

Multicopy effects of carR on exoenzyme synthesis. Plasmids pWU14203 and pSMG4 and the corresponding unmodified vectors (pSF6 and pDAH330, respectively) were used to transform the wild-type strain E. carotovora SCRI193 and various $\operatorname{Rex}^{-}$mutants described previously (Jones et al., 1993). Protease, pectate lyase and cellulase production by these strains was then assayed (Reeves et al., 1993) in the presence or absence of exogenously added OHHL.

\section{RESULTS}

\section{Complementation of the group 1 carbapenem mutants}

Table 1 shows a list of the $\mathrm{Car}^{-}$mutants assigned to group 1 or group 2 on the basis of their crossfeeding phenotype in the carbapenem bioassay. Group 2 mutants are regulatory mutants (carl) that are defective in OHHL synthesis and production of Car is restored by the addition of chemically synthesized OHHL (Bainton et al., 1992; Jones et al., 1993). In contrast, group 1 mutants still make OHHL and Car production is not restored by exogenously supplied OHHL. Because group 1 mutants make OHHL, and, importantly, because there were significantly more group 1 mutants than group 2 (regulatory, carl) mutants, we presumed that the former would be defective in the biosynthetic genes for carbapenem synthesis. We therefore attempted to clone these biosynthetic genes by direct cosmid complementation of group 1 mutants.

Of $350 \mathrm{Sp}^{\mathrm{r}}$ cosmid transductants of the group 1 $\mathrm{Car}^{-}$mutant PNP14, one had antibiotic production restored. The complementing cosmid (cWU142) was transferred into various chemically induced $\mathrm{Car}^{-}$mutants and only complemented group 1 mutants (Table 1). Complementation of the TnblaM-induced $\mathrm{Car}^{-}$mutants could not
Table 1. Construction and complementation analysis of various mutants of $E$. carotovora strain GS101

All strains were tested for the restoration of carbapenem production $(+)$ as indicated by a zone of clearing when spotted onto a lawn of supersensitive $E$. coli. \pm , only a very small halo present; NT, not tested - both complementing plasmid and mutant strain have the same antibiotic resistance marker.

\begin{tabular}{|lccccc|}
\hline \multirow{2}{*}{ Mutant } & Mutagen & Group & \multicolumn{3}{c|}{ Complementing plasmids: } \\
\cline { 3 - 6 } & & & & \multicolumn{3}{c|}{ cWU142 pWU14203 pSMG4 } \\
& & & + & + & + \\
PNP1 & NTG & 1 & + & + & + \\
PNP10 & NTG & 1 & + & + & + \\
PNP14 & NTG & 1 & + & + & + \\
PNP19 & NTG & 1 & + & + & + \\
PNP20 & NTG & 1 & + & - & - \\
PNP21 & EMS & 1 & + & - & \pm \\
PNP22 & EMS & 2 & - & - & \pm \\
PNP23 & EMS & 2 & - & - & + \\
PNP26 & EMS & 1 & + & + & \pm \\
MB1 & TnblaM & 2 & NT & NT & \pm \\
MB2 & TnblaM & 2 & NT & NT & \pm \\
MB3 & TnblaM & 1 & NT & NT & - \\
GS2 & TnblaM & 1 & NT & NT & - \\
JM1 & TnblaM & 1 & NT & NT & - \\
JMJ2 & TnblaM & 1 & NT & NT & + \\
JMJ3 & TnblaM & 1 & NT & NT & - \\
JMJ4 & TnblaM & 1 & NT & NT & - \\
JMJ5 & TnblaM & 1 & NT & NT & + \\
JMJ6 & TnblaM & 1 & NT & NT & - \\
JMJ7 & TnblaM & 2 & NT & NT & \pm \\
\hline & & & & & \\
\hline
\end{tabular}

be tested with the cWU142 cosmid because both carried the $\mathrm{Sp}^{\mathrm{r}}$ marker.

\section{Subcloning of the cWU142 cosmid and sequence analysis}

The cWU142 cosmid contained approximately $35 \mathrm{~kb}$ chromosomal DNA (data not shown). An EcoRI fragment of approximately $3.6 \mathrm{~kb}$ from cWU142 restored Car production in all of the chemically induced group 1 mutants, except mutant PNP21 (Fig. 1, Table 1). The resultant plasmid was called pWU14203 and, because it complemented six independently isolated group 1 mutants, we presumed that this carried most of the biosynthetic genes (except the one represented by the PNP21 mutation). The $3.6 \mathrm{~kb}$ insert fragment was sequenced and DNA analysis showed that approximately $2 \mathrm{~kb}$ of the fragment was derived from the original vector pSF6, and only approximately $1.6 \mathrm{~kb}$ was Erwinia chromosomal DNA (Figs 1 and 2). Within the $1.6 \mathrm{~kb}$, the major open reading frame (735 bp) encoded a $28136 \mathrm{Da}$ protein of 244 amino acids. This predicted protein showed low, but significant $(26.4 \%)$ sequence identity to the LuxR regulatory protein of $V$. fischeri and so was called CarR (Fig. 3). CarR becomes a member of the LuxR family, some of which have been shown to be positive 
cWU142:

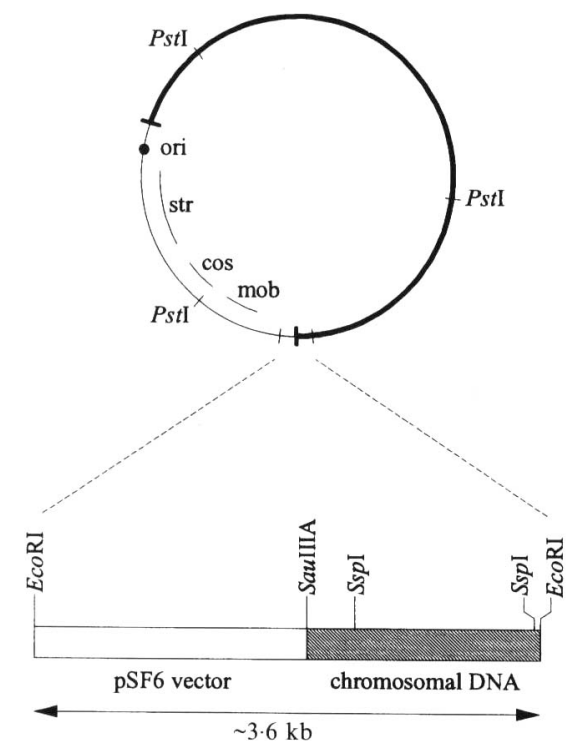

pSMG4:

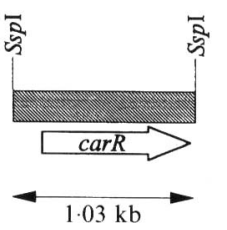

Fig. 1. Subcloning and localization of the car $R$ gene. The complementing cosmid, cWU142, was digested with EcoRI, and individual fragments cloned back into pSF6 digested with the same enzyme. One of the resulting plasmids, pWU14203 containing approximately $3.6 \mathrm{~kb}$ of insert DNA, was found to complement all but one of the Erwinia mutants. The insert of this plasmid was sequenced completely and found to contain one major open reading frame, carR. A $1.03 \mathrm{~kb}$ Sspl fragment was then cloned into pDAH330 digested with the same enzyme, to give plasmid PSMG4 .

transcriptional activators which are involved in the regulation of diverse physiological processes in various taxonomically unrelated bacteria (Fig. 3).

\section{Identification of the CarR protein}

To confirm that the car $\mathrm{R}$ gene alone was responsible for complementation of the group 1 mutants, and for the purposes of gene product identification, part of the $1.6 \mathrm{~kb}$ fragment of pWU14203 was subcloned into plasmid pDAH330 to generate pSMG4 (Fig. 1). The resultant plasmid was used to transform group 1 mutants and transformants were tested for complementation of the Car phenotype. The results confirmed that only car $\mathrm{R}$ was required for complementation in trans (Table 1). The $1.03 \mathrm{~kb} S s p \mathrm{I}$ fragment and others were cloned into a T7 expression system and used to identify the CarR product as a $28 \mathrm{kDa}$ protein, in agreement with the predicted size from sequence data (Fig. 4).

The results above confirmed that the six group 1 putative Car biosynthetic mutants induced by chemical muta- genesis were in fact regulatory mutants defective in the car R gene. We also tested for complementation of the TnblaM-induced $\mathrm{Car}^{-}$mutants after transformation with plasmid pSMG4. As shown in Table 1, the plasmid complemented only a subset (two/eight) of the mutants that had been assigned to group 1 by crossfeeding analysis. This suggested that these complemented TnblaM-induced mutants also had insertions in the car $R$ gene and confirmed that the group 1 mutants were divisible into carR regulatory mutants and putative car biosynthetic mutants. The carR and carI regulatory genes (Swift et al., 1993) lie on different cosmids and so are genetically unlinked.

\section{Molecular characterization of the carR mutations}

We attempted to isolate the chemically induced $c a r R$ mutations from the group 1 mutants by PCR amplification using primers which annealed to sequences upstream and downstream of the carR gene (Fig. 2). Curiously, we were unable to amplify any carR DNA from the chemically induced carR mutants, yet could amplify the correctly sized fragment (approximately $1.1 \mathrm{~kb}$ ) from the wild-type chromosome, from group $2 \mathrm{Car}^{-}$(carl) mutants and from group 1 mutant PNP21 (which is not defective in $\operatorname{car} R$ ) (data not shown). As the TnblaM-induced car $\mathrm{R}$ mutations also failed to amplify in the PCR reactions, we considered the possibility that the car $\mathrm{R}$ mutants isolated after chemical mutagenesis were actually due to large deletions or insertions, perhaps from a mobile genetic element.

All of the chemically induced $\mathrm{Car}^{-}$mutants were derived from strain GS101. This strain is a restrictionless and modificationless derivative of the progenitor ATCC39048 and was generated by random $\operatorname{Tn} 5$ mutagenesis (Bainton et al., 1992). Because GS101 carries a Tn 5 insertion we considered the possibility that the $\mathrm{Car}^{-}$mutants may have arisen due to secondary transposition of $\mathrm{Tn} 5$ into the $\operatorname{car} R$ gene. To test this hypothesis we attempted PCR-based amplification of $c a r R$ sequences using a car $R$ primer and a primer which hybridized to the terminus of $\operatorname{Tn} 5$ (see Methods). As predicted, using these primers we were able to amplify discrete fragments of car $\mathrm{R}$ from the various car $\mathrm{R}$ mutants. The sites of $\mathrm{Tn} 5$ insertion were confirmed by sequence analysis across each insertion point and are shown in Fig. 2. Interestingly, five of these Tn 5 insertions (in the independently isolated mutants PNP1, 10, 14, 19 and 20) are at exactly the same point (after the DNA encoding codon Asn ${ }_{166}$ ), with another (in mutant PNP26) 33 bases upstream of this common site. Thus, although the mutants carrying these $\operatorname{Tn} 5$ insertions had been independently isolated after EMS and NTG mutagenesis, they were due, in fact, to $\operatorname{Tn} 5$ ' hot spotting' into car R by secondary transposition. Probing EcoRI-digested chromosomal DNA from GS101, group 1 and group $2 \mathrm{Car}^{-}$ strains for sequence homology to Tn 5 showed that there were multiple (two to four) copies of $\operatorname{Tn} 5$ inserted in their respective chromosomes (data not presented), revealing a marked proclivity towards secondary hopping of the transposon in GS101 and its derivatives. However, neither of the two chemically induced group 2 (carl) mutants had Tn 5 insertions within carI because they 


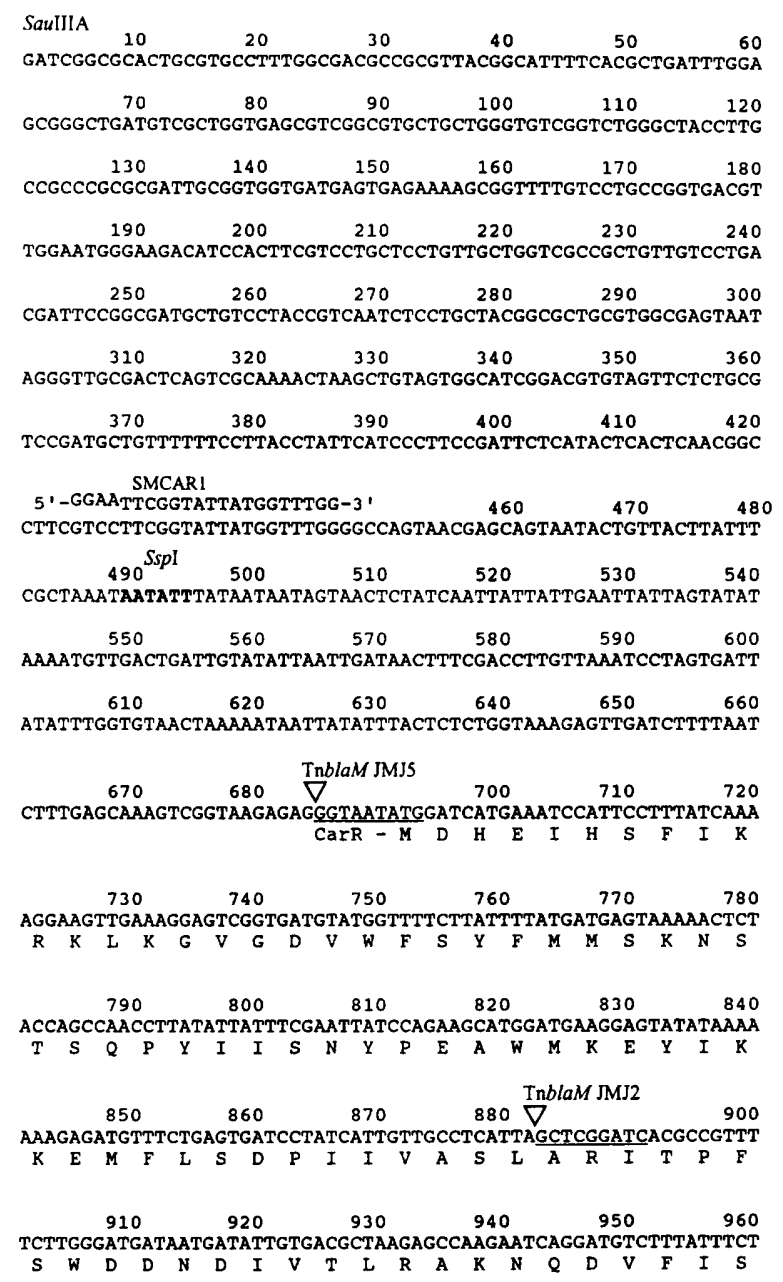

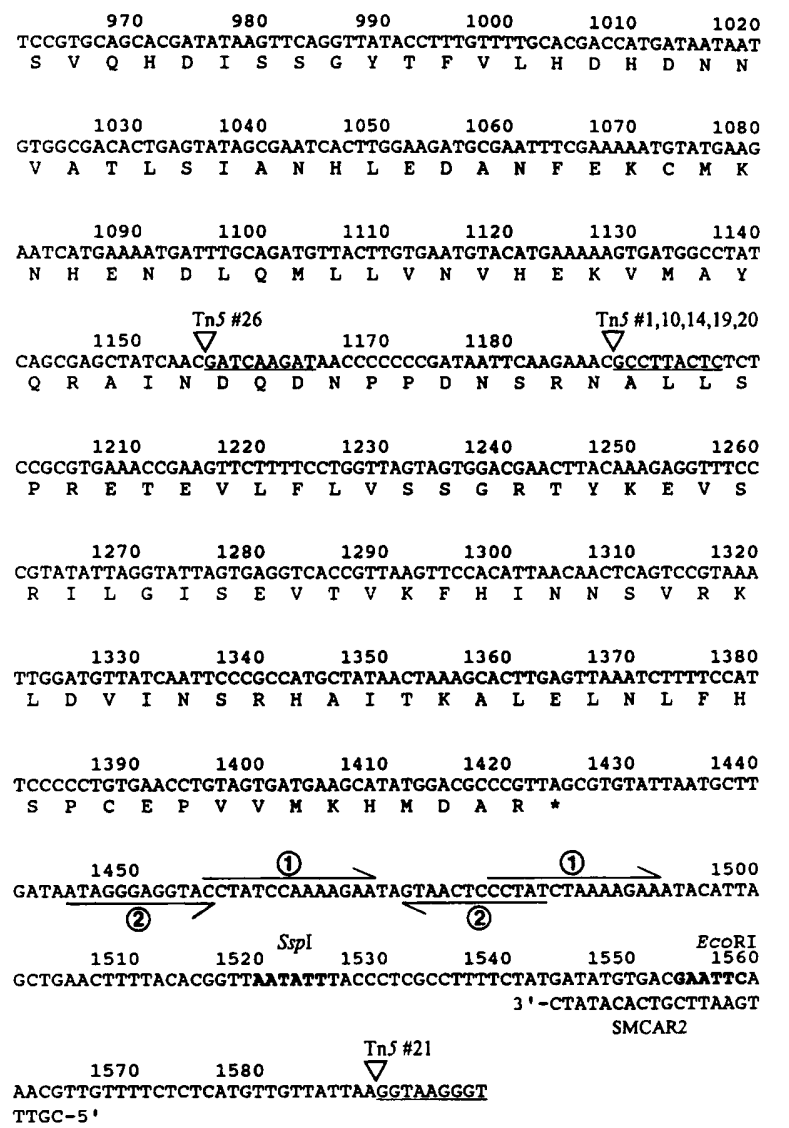

TTGC-5'

Fig. 2. Nucleotide sequence of the carR region of $E$. carotovora strain GS101. The sequence was generated by DNA sequence analysis of pWU14203 (to the EcoRI site at position 1554) and extended by cycle sequencing of a PCR-amplified portion of the chromosome of the mutant PNP21. The deduced amino acid sequence (single letter code) of the major open reading frame carR is shown below the nucleotide sequence. The positions of insertion of various transposons (as shown by an inverted triangle) have been indicated by convention upstream of the 9 bp repeated sequence generated upon insertion (underlined). The positions of two oligonucleotides, SMCAR1 and SMCAR2, have also been indicated. A pair of direct repeats and a pair of inverted repeats are located immediately downstream of carR ( 1 and 2, respectively).

produced the correct sized fragment by PCR analysis (data not presented). Thus, although the 'target' sizes of carI and $\operatorname{car} \mathrm{R}$ are similar (651 and $734 \mathrm{bp}$, respectively), and the phenotype scored in the bioassay screen, following mutagenesis was identical $\left(\mathrm{Car}^{-}\right)$, there was a disproportionate number of $c a r R$ mutations isolated which were due to $\operatorname{Tn} 5$ secondary hops.

The group $1 \mathrm{Car}^{-}$mutant PNP21 was complemented by cWU142, but not by pSMG4, and therefore was not a carR mutant. However, PCR amplification of the PNP21 chromosomal DNA with the $5^{\prime} \operatorname{car} R$ primer and a Tn 5 terminal primer did yield a product. On sequencing, the position of the Tn 5 insertion in mutant PNP21 was shown to be in the region $3^{\prime}$ of the car R termination codon and approximately 70 bases downstream of the $S_{s p I}$ site (Fig. 2). Computer translation of the DNA sequence around this region did not reveal any candidate translational start sites or obvious genes, so it is unclear whether or not this insertion lies within a car biosynthetic gene.

Two TnblaM-induced mutants (JMJ2 and JMJ5) were complemented by pSMG4. Cycle sequencing of PCRamplified chromosomal DNA revealed the JMJ5 insertion to be within the putative ribosome-binding site, $5^{\prime}$ of carR, and the JMJ2 insertion to be after the DNA encoding $\mathrm{Leu}_{64}$. Interestingly, although six of the seven Tn 5 secondary transposition-induced group 1 mutants were in carR, only two of the eight group $1 \mathrm{Tn} b l a M$ induced mutants were defective in car $R$. This apparently more random transposition of the TnblaM element could be an intrinsic product of its structure. However, as TnblaM is a derivative of $\operatorname{Tn} 5$ (Tadayyon \& BroomeSmith, 1992) it seems unlikely that it would transpose preferentially to different sites from the latter. Alternatively, because the $\operatorname{Tn} b l a M$ insertions are due to $\lambda$ mediated 'superinfection' of the transposon into the 


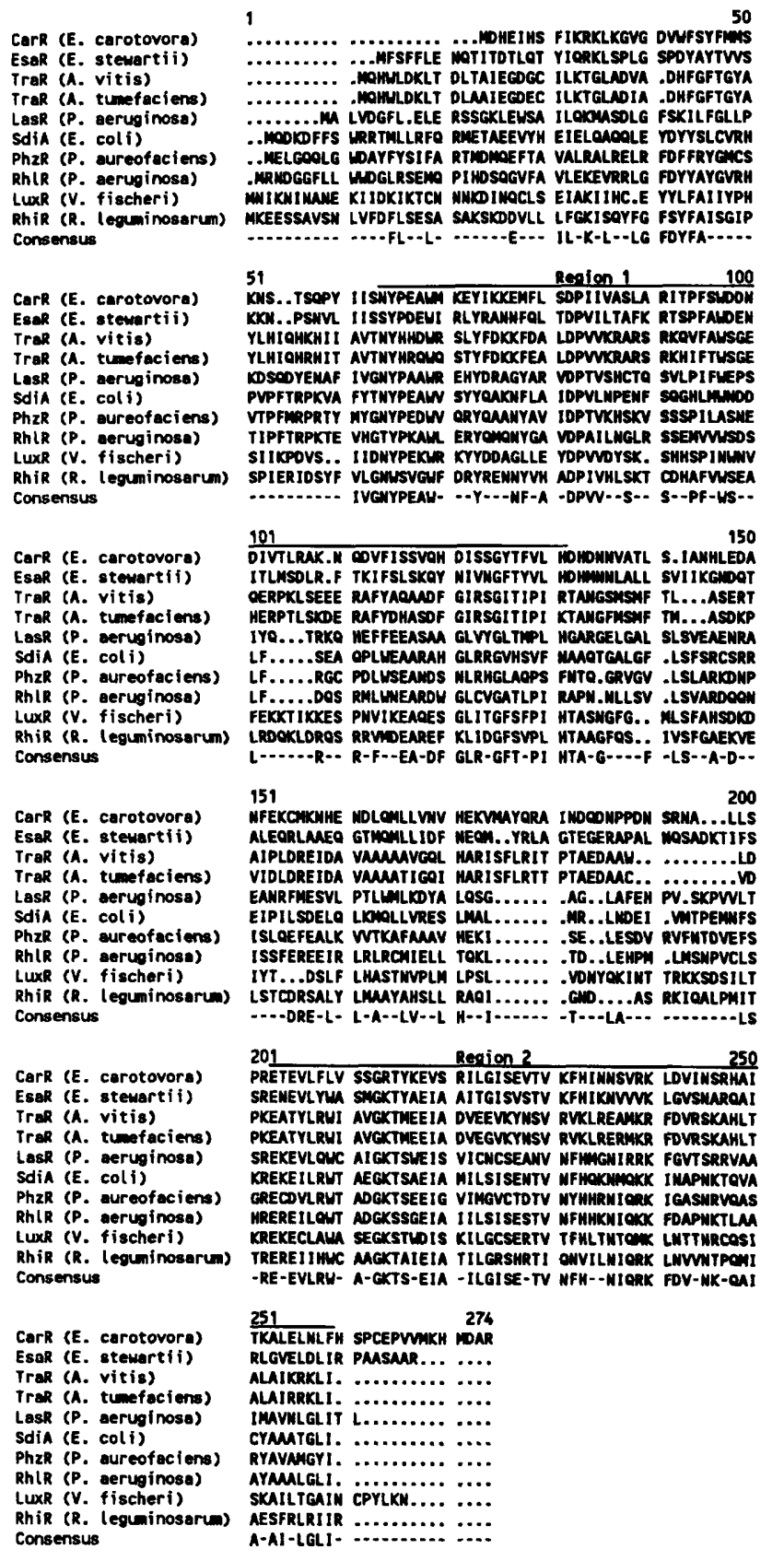

Fig. 3. Alignments of the predicted amino acid sequences of CarR (this work), EsaR (S. Beck von Bodman \& S. K. Farrand, unpublished; accession no. L32184), TraR (A. tumefaciens; W. C. Fuqua, C. M. Senzon \& S. C. Winans, unpublished; accession no. L08596), TraR (A. vitis; Fournier et al., 1994; accession no. P33909), LasR (Gambello \& Iglewski, 1991; accession no. M59425), SdiA (Sharma et al., 1986; accession no. P07026), PhzR (Pierson et al., 1994; accession no. L32729), RhIR (Ochsner et al., 1994; accession no. L08962), LuxR (Gray \& Greenberg, 1992; accession no. M96844) and RhiR (Cubo et al., 1992; accession no. M98835). Positions with four or more identical residues have been indicated as a consensus sequence. The proposed autoinducer-binding region and the DNA-binding region (regions 1 and 2, respectively) have been marked.

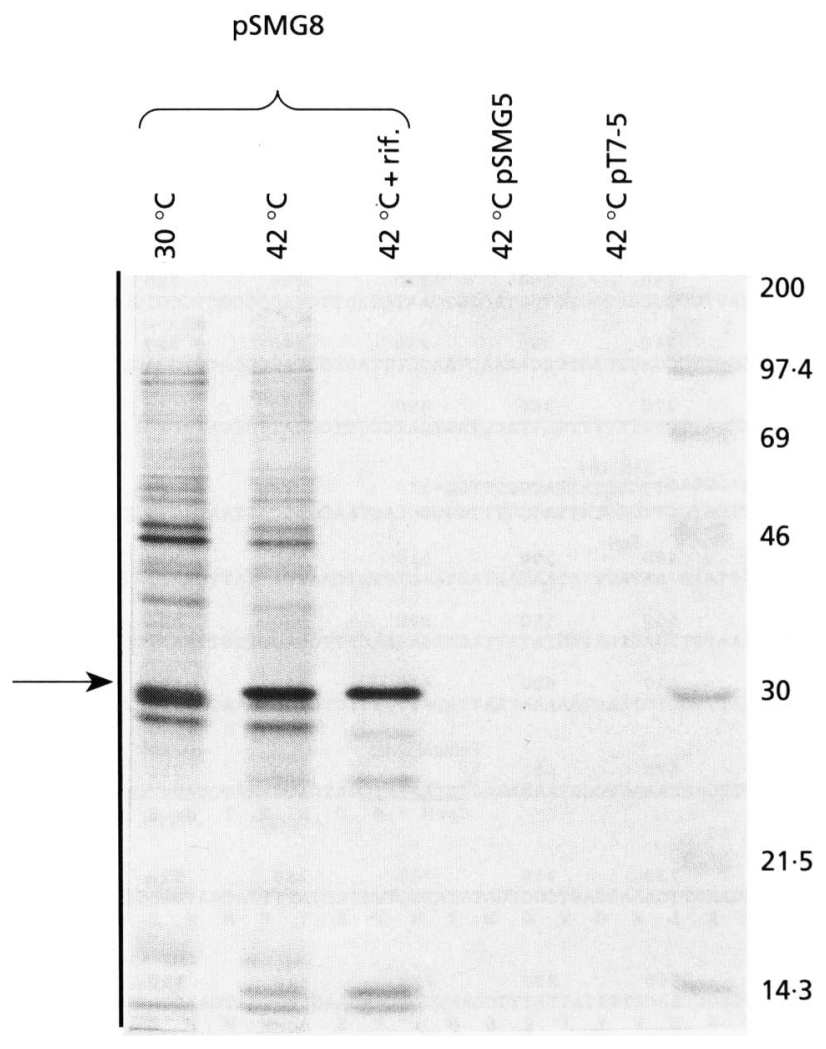

Fig. 4. Identification of the CarR protein in a T7 expression system. A $1.03 \mathrm{~kb}$ fragment encoding carR was cloned into pT7-5 in both orientations. In the correct orientation for expression of carR (pSMG8) and in the presence of rifampicin (rif; final concentration of $200 \mu \mathrm{g} \mathrm{ml}^{-1}$ ), only one major protein of approximately $30 \mathrm{kDa}$ was labelled (arrowed in lane 3). Under the same conditions, no proteins were labelled when either the fragment was cloned in the opposite orientation (pSMG5) or just vector alone was used (lanes 4 and 5 , respectively). Molecular size markers were run in lane 6 and their sizes in KDa have been indicated.

endogenous $\operatorname{Tn} 5$-containing background (as opposed to secondary transposition), this may have resulted in targeting of the incoming transposon to different sites.

\section{Effects of carR on the exoenzyme production phenotype}

Although the wild-type carR gene (pSMG4) complements the carR group 1 mutants of strain GS101 in the carbapenem bioassay, it did not complement group $2 \mathrm{Car}^{-}$ mutants for either antibiotic production or for exoenzyme synthesis $\left(\operatorname{Rex}^{-}\right)$. (Interestingly, however, with pSMG4 in the latter strains, very small/'intermediate' haloes were occasionally noted in the antibiotic bioassay; Table 1.) Similarly, both cWU142 and pWU14203 failed to restore exoenzyme production in either group $1\left(\mathrm{OHHL}^{+}\right)$or group 2 (OHHL ${ }^{-}$) $\mathrm{Rex}^{-}$mutants of strain SCRI193 (data not presented). Thus CarR appears to be a LuxR-type regulator which is specific for control of carbapenem antibiotic production.

Although car $R$ in low copy number had no noticeable effect on the Rex mutants of SCRI193, when carR was 


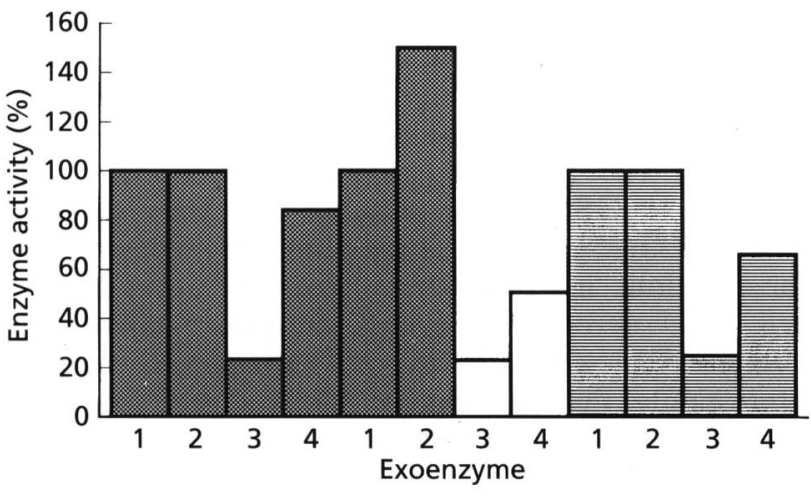

Fig. 5. Effect of carR in multicopy on exoenzymes in $E$. carotovora strain SCRI193. Protease (橉), pectate lyase ( $\square$ ) and cellulase (圆) production was assayed in triplicate in the presence of either pDAH330 (1) or pSMG4 (3). The same strains were also assayed for exoenzyme production in the presence of exogenously added OHHL ( 2 and 4 , respectively). The values obtained for SCRI193 (pDAH330) were taken as $100 \%$. Other values were then calculated as a percentage of this control value.

present on a high copy number plasmid (pSMG4) it reduced exoenzyme synthesis levels in the wild-type strain (Fig. 5) and exacerbated the Rex phenotype in $\operatorname{Rex}^{-}$ mutants (data not shown). However, this effect was at least partially remedied by the addition of exogenous OHHL to the test strains. These results suggest that excessive amounts of the CarR protein can interfere with the global regulation of the exoenzymes, at least in strain SCRI193 and its derivatives.

\section{DISCUSSION}

The majority of the group $1 \mathrm{Car}^{-}$mutants of E. carotovora were not defective in the antibiotic biosynthetic genes but were mutant for carR. The $28 \mathrm{kDa}$ CarR protein is homologous with the transcriptional activator LuxR of $V$. fischeri (Devine et al., 1989; Engebrecht \& Silverman, 1984). LuxR acts in concert with OHHL to activate the lux genes in that organism. Thus it seems likely that a similar CarR: OHHL interaction is also required for carbapenem antibiotic gene expression in E. carotovora.

Although CarR function is clearly OHHL-dependent under normal physiological conditions, on occasion we did observe that pSMG4 enabled group 2 mutants of GS101 to produce very slight haloes in the carbapenem bioassay (e.g. $1-2 \mathrm{~mm}$, cf. $8-10 \mathrm{~mm}$ in the wild-type) (Table 1). Although this effect was sporadic and obviously was not a complementation of the carI defect, this observation implies that the CarR protein, in very high copy, can function partially in the absence of OHHL.

CarR joins a rapidly growing family of LuxR homologues which are required for regulation of diverse physiological traits, e.g. LasR (elastase regulation in Pseudomonas); TraR (regulation of Ti plasmid conjugal transfer in Agrobacterium); SdiA (regulation of cell division gene expression in E. coli); RhiR (regulation of rhizosphere-specific genes in Rbizobium); RhlR (regulation of rhamnolipid biosurfactant synthesis in Pseudomonas); and, recently, PhzR (regulation of phenazine antibiotic synthesis in Pseudomonas) (Fuqua et al., 1994; Swift et al., 1994; Pierson et al., 1994). All of these results strongly suggest that the CarR protein acts as a positive transcriptional activator of the carbapenem biosynthetic genes. Our results also show that car $\mathrm{R}$ must function in trans and so must lie in a different transcriptional unit from the biosynthetic genes. Also, because CarR does not complement the $\mathrm{Rex}^{-}$ phenotype in either the cognate strain or another Erwinia strain (SCRI193) it seems likely that CarR is specific to the activation of the carbapenem biosynthesis genes. However, in multicopy, Car $R$ caused a reduction in the production of pectinases, cellulases and proteases in wildtype SCRI193, effectively mimicking the $\mathrm{Rex}^{-}$phenotype (Fig. 5). In addition, multicopy CarR exacerbated the Rex ${ }^{-}$ phenotype in $\mathrm{Rex}^{-}$mutants although growth rate was unaffected (data not presented). High copy CarR might produce these effects by sequestering some of the OHHL that would normally function in the regulation of the Rex phenotype or, alternatively, CarR protein in excess could interfere directly with genes or proteins of the Rex regulatory system. However, the exoenzyme down regulation phenotypes of the wild-type SCRI193 (pSMG4) or the $\mathrm{Rex}^{-}$mutants carrying pSMG4 were partially restored by exogenously supplied OHHL (Fig. 5), consistent with the model in which the naturally produced OHHL is sequestered by excess CarR. These results also imply that at least one other homologue of LuxR exists in the Rex regulon and that artificially high amounts of CarR compete with this (these) for available OHHL. [It is interesting in this context that we have recently identified another LuxR homologue in SCRI193 encoded by a gene which is contiguous with carI and transcribed convergently with it (S. Jones, unpublished) and similar results have been found for another E. carotovora strain in which the expI gene (carI homologue) is linked to another lux $R$ homologue, $\operatorname{expR}$ (EMBL database accession number X72891).] Surprisingly, in contrast to the effects of multicopy CarR in SCRI193, in the cognate wild-type strain (GS101) there was no significant effect on exoenzyme synthesis implying that there must be subtle differences in the overall mode of global regulation of the virulence factors in the two strains. The molecular basis of these differences is currently unknown.

For several of the $N$-acyl homoserine lactone regulated phenotypes described above, a LuxI homologue partner has been identified in the respective host, e.g. LuxI/LuxR (V. fischeri), LasI/LasR (P. aeruginosa), TraI/TraR (Agrobacterium tumefaciens) and, very recently, PhzI/PhzR $(P$. aureofaciens) (Fuqua et al., 1994; Swift et al., 1994; Pierson et al., 1994). However, neither a LuxI homologue 'partner', nor a defined signalling molecule, has been identified to date for either the E. coli SdiA or Rbizobium leguminosarum RhiR systems, and whether or not the LasI regulator gene plays a role in RhlR-mediated activation of rhamnolipid synthesis in $P$. aeruginosa was not discussed by Ochsner et al. (1994).

Unlike $\operatorname{lu} x I$ and $\operatorname{lux} \mathrm{R}$ in $V$. fischeri (e.g. see Meighen, 
1991; Meighen \& Dunlap, 1993), the carI and carR regulatory genes in E. carotovora are not linked. Although carR mutants are only apparently affected in carbapenem production, carI mutants have very pleiotropic phenotypes (down regulation in synthesis of pectinases, cellulases and proteases, and loss of carbapenem production) confirming that the ultimate product (OHHL) of a single carI locus acts to control multiple, physiologically unrelated phenotypes by (indirect) transcriptional activation of many genes. The only common feature of these $N$-acyl homoserine lactone regulated phenotypes is a growthphase/cell-density dependency, and that arises naturally from the cell-density dependency of OHHL synthesis (Williams et al., 1992; Swift et al., 1993).

How can OHHL regulate multiple genes? A simple way in which to link the cell-density-dependent (OHHLdependent) control of multiple, diverse phenotypes would be to have multiple LuxR homologues in a single cell which are all responsive to the same signalling molecule. At least some of these LuxR homologues might be 'dedicated' transcriptional activators in that they act, directly or indirectly, specifically on their respective target genes, e.g. carbapenem synthesis genes (controlled by CarR) or exoenzyme genes (a hypothetical RexR?) in E. carotovora. The validity of this model is currently being assessed.

LuxR is essentially a two domain protein (Slock et al., 1990; Fuqua et al., 1994), and based on the LuxR model we expect that the LuxR homologues will also bind their respective $\mathrm{N}$-acyl homoserine lactones in the $\mathrm{N}$-terminal domain and will bind to their respective target DNA sequences via their $\mathrm{C}$-terminal domains. In this context, it is interesting that the most conserved residues of the LuxR homologues lie within the putative $\mathrm{N}$-acyl homoserine lactone and DNA-binding domains (Fig. 3; see Fuqua et al., 1994).

The recent observation (Pierson et al., 1994) that phenazine antibiotic production by $P$. aureofaciens is regulated by the LuxI/LuxR homologues, PhzI/PhzR, suggests some interesting analogies and comparisons with carbapenem antibiotic regulation in E. carotovora. Both antibiotics are secondary metabolites, their synthesis being growthphase-dependent because they are regulated by prior production of a small signalling molecule. In the case of $P$. aureofaciens, the $p h z I$ and $p h q R$ regulatory genes are linked, although they are not contiguous (Pierson et al., 1994). In contrast, the carI and car $R$ regulatory genes of E. carotovora are unlinked. The phenazine biosynthetic genes are linked to the $p h z I / R$ locus (Pierson et al., 1994), and the preliminary genetic results described here suggest that at least some of the carbapenem biosynthetic genes may be linked to $c a r R$. This is currently under investigation.

Finally, it is very interesting that, although most of the $c a r R$ mutants were isolated after chemical mutagenesis, they arose because of $\operatorname{Tn} 5$ secondary transposition in the GS101 parent strain. In contrast, the chemically induced Car mutants with carI mutations did not carry $\operatorname{Tn} 5$ insertions and were, presumably, due to mis-sense mutations. The 'target' size of the carR gene (735 bp) is similar to that of carI ( $651 \mathrm{bp}$ ) yet in all of our mutagenesis experiments we have found a disproportionate number of carR mutants (relative to carI mutants). Therefore, these data suggest strongly that the car $\mathrm{R}$ gene acts as a 'hot spot' for Tn 5 insertion, at least in secondary transpositions in GS101. We presume that chemical mutagenesis indirectly stimulates the general level of secondary transposition in this strain thereby revealing the carR:: $\operatorname{Tn} 5$ derivatives at high frequency among survivors, when screened in the carbapenem bioassay. Interestingly, the common site for $\operatorname{Tn} 5$ insertion in carR lies within the sequence encoding the 'hinge' region of the CarR protein upstream of the conserved DNAbinding motifs (Figs 2 and 3). Based on information derived from the LuxR protein (Slock et al., 1990; Fuqua et al., 1994), the OHHL-binding site is likely to be in the $\mathrm{N}$-terminal domain and the DNA-binding site in the Cterminal domain of CarR. If we view the LuxR family of proteins as effectively modular in this way, then is it possible that a highly recombinogenic region in the corresponding gene could act as a source of generation of ' $R$ ' protein diversity and evolution? This would be especially important if the genes encoding the LuxR homologues could move horizontally. In this respect it is interesting that the carR gene has a GC ratio of $39 \cdot 2 \%$ (data not presented), which is significantly different from the overall GC content of E. carotovora $(52.1 \%$; Starr \& Chatterjee, 1972).

\section{ACKNOWLEDGEMENTS}

We thank David Hodgson for plasmid pDAH330 and Matthew Holden, Nick Thomson, Tony Cox and Phil Reeves for useful discussions.

This work was supported by the SERC BTD awards GR/H99370 and GR/H93231, and the AFRC award PO1449.

\section{REFERENCES}

Bainton, N. J., Stead, P., Chhabra, S. R., Bycroft, B. W., Salmond, G. P. C., Stewart, G. S. A. B. \& Williams, P. (1992). $N$-(3-oxohexanoyl)-L-homoserine lactone regulates carbapenem antibiotic production in Erwinia carotovora. Biochem J 288, 997-1004.

Bycroft, B. W. (1988). Dictionary of Antibiotics and Related Substances. London: Chapman \& Hall.

Bycroft, B. W., Maslen, C., Box, S. J., Brown, A. \& Tyler, J. W. (1987). The isolation and characterisation of (3R,5R)-carbapenem3-carboxylic and (3S,5R)-carbapenem-3-carboxylic acid from Serratia and Erwinia species and their putative biosynthetic role. $J$ Chem Soc Chem Commun 21, 1623-1625.

Bycroft, B. W., Maslen, C., Box, S. J., Brown, A. \& Tyler, J. W. (1988). The biosynthetic implications of acetate and glutamate incorporation into $(3 \mathrm{R}, 5 \mathrm{R})$-carbapenem-3-carboxylic acid and (5R)carbapenem-em-3-carboxylic acid by Serratia sp. J Antibiotics 41, 1231-1242.

Cao, J. G. \& Meighen, E. A. (1989). Purification and structural identification of an autoinducer for the luminescence system of Vibrio harveyi. J Biol Chem 264, 21670-21676.

Chen, T. S., Arison, B. H., Ruby, C. L., Dombrowski, A. W. \& Inamine, E. S. (1993). A cofactor for thienamycin biosynthesis produced by a blocked mutant of Streptomyces cattleya. J Ind Microbiol $12,66-67$. 
Cubo, M. T., Economou, A. N., Murphy, G. J., Johnston, A. W. \& Downie, J. A. (1992). Molecular characterisation and regulation of the rhizosphere-expressed genes $\operatorname{rbi} A B C R$ that can influence nodulation by Rhizobium leguminosarum biovar viciae. J Bacteriol 174, 4026-4035.

Devine, J. H., Shadel, G. S. \& Baldwin, T. O. (1989). Identification of the operator of the lux regulon from the Vibrio fischeri ATCC7744. Proc Natl Acad Sci USA 86, 5688-5692.

Eberhard, A., Burlingame, A. L., Eberhard, C., Kenyon, G. L., Nealson, K. H. \& Oppenheimer, N. J. (1981). Structural identification of autoinducer of Photobacterium fischeri luciferase. Biochemistry 20, 2444-2449.

Ellard, F. M., Cabello, A. \& Salmond, G. P. C. (1989). Bacteriophage lambda-mediated transposon mutagenesis of phytopathogenic and epiphytic Erwinia species is strain dependent. Mol \& Gen Genet 218, 491-498.

Engebrecht, J. \& Silverman, M. (1984). Identification of genes and gene products necessary for bacterial bioluminescence. Proc Natl Acad Sci US A 81, 4154-4158.

Fournier, P., De Ruffray, P. \& Otten, L. (1994). Natural instability of an Agrobacterium vitis 'Ti plasmid due to unusual duplication of a 2.3 kb DNA fragment. Mol Plant-Microbe Interact 7, 164-172.

Fuqua, W. C., Winans, S. C. \& Greenberg, E. P. (1994). Quorum sensing in bacteria - the lux R-luxI family of cell density-responsive transcriptional regulators. J Bacteriol 176, 269-275.

Gambello, M. J. \& Iglewski, B. H. (1991). Cloning and characterisation of the Pseudomonas aeruginosa lasR gene, a transcriptional activator of elastase expression. J Bacteriol 173, 3000-3009.

Gray, K. M. \& Greenberg, E. P. (1992). Sequencing and analysis of $\operatorname{lu} x \mathrm{R}$ and $l u x I$, the luminescence regulatory genes from the squid light organ symbiont Vibrio fischeri ES114. Mol Marine Biol Biotechnol 1, 414-419.

Hanahan, D. (1983). Studies on transformation of Escherichia coli with plasmids. $J$ Mol Biol 166, 557-580.

Hinton, J. C. D. \& Salmond, G. P. C. (1987). Use of Tnpho $A$ to enrich for extracellular enzyme mutants of Erwinia carotovora subspecies carotovora. Mol Microbiol 1, 381-386.

Jones, S., Yu, B., Bainton, N. J., Birdsall, M., Bycroft, B. W., Chhabra, S. R., Cox, A. J. R., Golby, P., Reeves, P. J., Stephens, S., Winson, M. K., Salmond, G. P. C., Stewart, G. S. A. B. \& Williams, P. (1993). The $\operatorname{lux}$ autoinducer regulates the production of exoenzyme virulence determinants in Erwinia carotovora and Pseudomonas aeruginosa. EMBO J 12, 2477-2482.

Kitano, K., Nozaki, Y. \& Imada, A. (1985). Selective accumulation of unsulfated carbapenem antibiotics by sulfate transport-negative mutants of Streptomyces griseus subsp. cryophilus C-19393. Agric Biol Chem 49, 677-684.

Livermore, D. M. (1993). Carbapenemases: the next generation of $\beta$-lactamases? ASM News 59, 129-135.

Meighen, E. A. (1991). Molecular biology of bacterial bioluminescence. Microbiol Rev 55, 123-142.

Meighen, E. A. \& Dunlap, P. V. (1993). Physiological, biochemical and genetic-control of bacterial bioluminescence. Adv Microb Physiol 34, 1-67.

Miller, J. H. (1972). Experiments in Molecular Genetics. Cold Spring Harbor, NY: Cold Spring Harbor Laboratory.

Mulholland, V. \& Salmond, G. P. C. (1995). Use of coliphage $\lambda$ and other bacteriophages for molecular genetic analysis of Erwinia and related Gram-negative bacteria. In Methods in Molecular Genetics, Molecular Microbiology Techniques, Part B. Edited by K. Adolph. Orlando, FL: Academic Press (in press).
Naas, T. \& Nordmann, P. (1994). Analysis of a carbapenemhydrolysing class A $\beta$-lactamase from Enterobacter cloacae and of its LysR-type regulatory protein. Proc Natl Acad Sci USA 91, 7693-7697.

Ochsner, U., Koch, A., Fiechter, A. \& Reiser, J. (1994). Isolation and characterisation of a regulatory gene affecting rhamnolipid biosurfactant synthesis in Pseudomonas aeruginosa. J Bacteriol 176, 2044-2054.

Parker, W. L., Rathnum, M. L., Wells, J. S., Trejo, W. H., Principe, P. A. \& Sykes, R. B. (1982). SQ27850, a simple carbapenem produced by species of Serratia and Erwinia. $J$ Antibiotics 35, 653-660.

Passador, L., Cook, J. M., Gambello, M. J., Rust, L. \& Iglewski, B. H. (1993). Expression of Pseudomonas aeruginosa virulence genes requires cell-to-cell communication. Science 260, 1127-1130.

Pierson, L. S., III, Keppenne, V. D. \& Wood, D. W. (1994). Phenazine antibiotic biosynthesis in Pseudomonas aureofaciens 30-84 is regulated by PhzR in response to cell density. $J$ Bacteriol 176, 3966-3974.

Piper, K. R., Beck von Bodman, S. \& Farrand, S. K. (1993). Conjugation factor of Agrobacterium tumefaciens regulates Ti plasmid transfer by autoinduction. Nature 362, 448-450.

Pirhonen, M., Flego, D., Heikinheimo, R. \& Palva, E. T. (1993). A small diffusible signal molecule is responsible for the global control of virulence and exoenzyme production in the plant pathogen Erwinia carotovora. EMBO J 12, 2467-2476.

Reeves, P. J., Whitcombe, D., Wharam, S., Gibson, M., Allison, G., Bunce, N., Barallon, R., Douglas, P., Mulholland, V., Stevens, S., Walker, D. \& Salmond, G. P. C. (1993). Molecular cloning and characterization of 13 out genes from Erwinia carotovora subspecies carotovora: genes encoding members of a general secretion pathway (GSP) widespread in Gram-negative bacteria. Mol Microbiol 8, 443-456.

Sanger, F., Nicklen, S. \& Coulson, A. R. (1977). DNA sequencing with chain-terminating inhibitors. Proc Natl Acad Sci USA 74, 5463-5467.

Selvaraj, G., Fong, Y. C. \& lyer, V. N. (1984). A portable DNA sequence carrying the cohesive site (cos) of bacteriophage lambda and the mob (mobilization) region of the broad-host range plasmid RK2: a module for the construction of new cosmids. Gene 32, 235-241.

Sharma, S., Stark, T. F., Beattie, W. G. \& Moses, R. E. (1986). Multiple control elements for the uvrC gene of Escherichia coli. Nucleic Acids Res 14, 2301-2318.

Slock, J., Vanriet, D., Kolibachuk, D. \& Greenberg, E. P. (1990). Critical regions of the Vibrio fischeri LuxR protein defined by mutational analysis. J Bacteriol 172, 3974-3979.

Starr, M.P. \& Chatterjee, A. K. (1972). The genus Erwinia: enterobacteria pathogenic to plants and animals. Annu Rev Microbiol 26, 389-426.

Swift, S., Winson, M. K., Chan, P. F., Bainton, N. J., Birdsall, M., Reeves, P. J., Rees, C. E. D., Chhabra, S. R., Hill, P. J., Throup, J. P., Bycroft, B. W., Salmond, G. P. C., Williams, P. \& Stewart, G. S. A. B. (1993). A novel strategy for the isolation of luxI homologues: evidence for the widespread distribution of a $\operatorname{lu} x \mathrm{R}: \operatorname{lu} x I$ superfamily in enteric bacteria. Mol Microbiol 10, 511-520.

Swift, S., Bainton, N. J. \& Winson, M. K. (1994). Gram-negative bacterial communication by $N$-acyl homoserine lactones: a universal language? Trends Microbiol 2, 193-198.

Tabor, S. \& Richardson, C. C. (1985). A bacteriophage-T7 RNA polymerase promoter system for controlled exclusive expression of specific genes. Proc Natl Acad Sci US A 82, 1074-1078. 
Tadayyon, M. \& Broome-Smith, J. K. (1992). TnblaM: a transposon for directly tagging bacterial genes encoding cell envelope and secreted proteins. Gene 111, 21-26.

White, F. F., Klee, H. J. \& Nester, E. W. (1983). In vivo packaging of cosmids in transposon-mediated mutagenesis. J Bacteriol 153, 1075-1078.

Williams, P., Bainton, N. J., Swift, S., Winson, M. K., Chhabra, S. R., Stewart, G. S. A. B., Salmond, G. P. C. \& Bycroft, B. W. (1992). Small molecule mediated density dependent control of gene expression in prokaryotes: bioluminescence and the biosynthesis of carbapenem antibiotics. FEMS Lett 100, 161-168.
Williamson, J. M., Inamine, E., Wison, K. E., Douglas, A. W., Liesch, J. M. \& Albers-Schonberg, G. (1985). Biosynthesis of the $\beta$ lactam antibiotic, thienamycin, by Streptomyces cattleya.J Biol Chem 260, 4637-4647.

Zhang, L., Murphy, P. J., Kerr, A. \& Tate, M. E. (1993). Agrobacterium conjugation and gene regulation by $N$-acyl-L-homoserine lactones. Nature 362, 446-448.

Received 29 September 1994; revised 18 November 1994; accepted 23 November 1994. 